\title{
What Venture Capital Can Do for Your Company
}

\section{Eapen Chacko (Queblo, Inc.)}

\author{
KEYWORDS: Information, Software, Data, Health Care \\ \& Biotech, Entrepreneurship, Innovation, Finance, \\ Venture Capital, Technology Commercialization.
}

The financial market can be daunting for new entrepreneurs. Anyone who tries to be a part of it without understanding how it works, the players on the buy and sell sides, and their economic motivations won't see much in potential gains. Today screaming pundits talk incessantly about public markets, where everybody has an opinion, and everyone seems to know someone who is involved with venture capital or who is a venture capitalist. Yet these same individuals often lack even a basic understanding of the market and its dynamics, or its players and what they do. Here is a primer.

\section{Introduction}

Venture capital is a distinct subset of the alternative asset class called private equity. Global assets under management in private equity funds are approximately $\$ 3.8$ trillion, according to Prequin. ${ }^{[1]}$ In 2014, $\$ 495$ billion was raised worldwide for private equity, and about $\$ 48$ billion of the total flowed to venture capital investment funds. The $\$ 48$ billion was spread across 4,300 deals, or about $\$ 11.2$ million per deal on average.

Venture capital firms look to fund early stage companies that are pre-revenue, or with limited revenues; these companies often lack collateral and therefore not bankable through traditional lending channels. However, companies that garner venture investment are judged to be capable of quickly achieving significant shares of markets greater than a billion dollars. In addition to strong management teams, these target companies typically have strong intellectual property, a saleable software solution, an innovative product or a way of disrupting a large market for traditional services.

Venture investment has helped create many of our leading public companies, especially in the technology arena. In recent years, investment has funneled into a relatively narrow range of sectors like web-based marketing, social media and consumer internet companies. Institutional investors have increasingly been forced to raise their allocations to "alternative investments," including commodities, real assets, hedge funds of all stripes, private equity and venture capital, as they seek higher returns in a post-financial crisis environment of low rates and higher valuations.

The venture capital funding model can point to many well-known success stories, but it is useful to look at the venture capital scorecard from the perspectives of public and private economics and innovation; as well as from the suppliers of capital -- namely public and private pension funds, endowment funds and high net worth individuals. Venture capital funding has indeed created enduring companies, tax revenues for governments, technological innovation and employment for hundreds of thousands of households, as well as providing excess returns for early providers of capital. A well- functioning venture funding model should provide value, on better terms, to many stakeholder constituencies.

\section{A Golden Age for Venture Capital}

America continues to nurture home-grown entrepreneurs, as well as attracting the best from all around the world. Our capital markets have an exemplary history of funding innovative companies through the combination of venture capital, boutique investment banks and capital markets that were receptive to IPOs from small issuers.

Apple, for example, was founded in 1976, and it received venture funding from Sequoia Capital ${ }^{[2]}$ in Silicon Valley in 1978. In December 1980, the relatively small, tech-focused investment bank Hambrecht \& Quist, along with Morgan Stanley, brought Apple public, raising $\$ 90$ million to expand the production and sale of Apple II personal computers. At the time Apple had revenues of $\$ 117$ million and net income of $\$ 12$ million.

By the end of 2004, Apple's market capitalization was $\$ 26$ billion, leading the 25 companies by this measure; 
by $12 / 31 / 2014$, the market cap of AAPL had reached an astounding $\$ 347$ billion! During this ten year period, Apple's EPS increased at a compound annual rate of $56 \%$, according to GSV Capital. Venture capital, for this company, funded a strong management team with visionary products, innovative marketing and fast timeto-market in an infant PC industry; Hambrecht \& Quist put the company's shares into the hands of public investors after only two years in a venture portfolio. This much-admired global technology leader became one of the top-performing public companies for the decade ending 2014.

During this golden age, venture funding helped spawn many other mature, global leading tech companies such as Microsoft, Oracle, Intel and Cisco. As equity markets opened to global capital flows, these market leaders dominated their segments and grew their sales and earnings accordingly, while valuation multiples rose at the same time. As a result, technology stocks account for a 55\% weighting in the NASDAQ 100 Index, and the shares of Apple, Microsoft, Intel and Cisco rank among the top 10 weighted companies as of 2/27/15, combining to account for $31.25 \%$ of the index. Although the growth rates of these companies have slowed, strong cash flows, along with a stream of increasing dividends and share buybacks, have combined to keep them attractive investments some $\mathbf{3 0}$ years after their founding!

These companies and many others innovated in their sectors, generated significant Federal, state and local tax revenues, created enormous private wealth and accounted for a significant portion of equity and fixed income mutual fund performance over decades. Mutual funds represent about $23 \%$ of household financial assets in the U.S.; and defined contribution benefit plans have about $60 \%$ of their assets in mutual funds -so the wealth effects from creating these companies have been widely dispersed among individual households.

The American venture capital model's performance hit on all cylinders during this golden age. However, success in financial markets breeds all manner of changes to the markets themselves and to the behavior of market participants. Not all these market-driven changes have been unambiguously for the better.

\section{Markets Super-Size and Expectations Follow}

From 1995-2014, public markets generally boomed. Even prosaic investments like bonds, driven by a secular decline in interest rates, generated an average annual return of $6.2 \%$ during this period. Large cap stocks, including our tech giants identified above, generated average annual returns of $10 \%$. Inflation rates fell and remained benign during this period, raising real returns for investors.

Institutional investors, particularly state and local pension funds, university endowment funds, foundations and others weren't satisfied with very healthy public market returns. In heady markets, investors chase performance. If a balanced portfolio of liquid, public investments could produce average returns of $8 \%$, ambitious managers actively looked for ways to generate better returns for themselves and for their constituents.

Dave Swensen, the chief investment officer of the Yale Endowment, prominently put forward the "Yale Model," which featured very high portfolio allocations to alternative asset classes, particularly private equity, including venture capital; in 2014, the Yale Endowment's allocation to private equity was $31 \%$ of assets!

According to statistics from J.P. Morgan Asset Management, for the years 2005-2007, private equity's annual returns, as an asset class, were $28.4 \%, 28.7 \%$, and $19.5 \%$, respectively; for the 10 years ending $3 / 31 / 2015$, J.P. Morgan says that private equity's average annual returns were $15 \%$ with an annual volatility of $10.1 \%$.

The capital markets changed dramatically with a global ocean of money looking for these higher returns, and an explosion of institutional private equity fund sponsors. Along with them came armies of consultants, advisers and lawyers. Public and private pension funds, along with foundations and smaller endowments, were all hellbent for leather trying to incorporate the principles of the Yale Model into their portfolio allocations, with the expectations of returns like those cited above.

The super-sizing of equity capital markets eventually meant the demise of smaller, independent boutique investment banks, like Hambrecht \& Quist, Robertson Stephens and many others that underwrote venture capital portfolio companies as they exited by becoming public companies. Instead, investment banks became 
much larger, global entities, which was certainly a plus for Fortune 100 companies looking for efficiencies in financial, treasury and corporate services through their investment banks. Now the minimum acceptable deal sizes became significantly larger, which meant that some companies stayed in venture portfolios longer than planned, with a sale to a strategic buyer being the only potential exit.

\section{Success in VC Investing: Find the High Performers and Overcome High Fees}

On the venture capital side of private equity, historical performance data are of very poor quality by public standards, relying on metrics like "upper quartile performance" and internal rates of return (IRRs). Most marketing materials and consultant performance reports do not meet the standards of the CFA Institute's "Global Investment Performance Standards," considered the preferred international benchmark for performance measurement. Information about fees and sponsor costs are incomplete, inconsistent and opaque. The fee structure is expensive and not aligned well with the interests of investors.

Since the golden age of venture investing, the venture capital fund fee model is a "2/20" structure, where $2 \%$ of the fund's committed capital goes to the general partners of the venture firm, regardless of whether the venture firm has two employees or 50 employees. Additionally, $20 \%$ of any investment gains are paid to the general partners. Bear in mind that typically general partners of the venture firms invest less than $1 \%$ of their own wealth into individual funds. To an institutional investor in public markets, the lack of stock ownership by the CEO of a portfolio company would be viewed as a negative, not having "skin in the game." But on the venture capital/private equity side, no such alignment of commitment is required by investors.

Research also shows that the 2/20 model leads to venture firms focusing on raising their next fund a few years into the life of their last fund; if the carry on the last fund has been growing, the focus on raising a bigger, new fund increases because of the faster value accretion in the existing fund. Investors argue that the venture firm's attentions are divided and not focused on managing existing portfolios.

The way superior results accrue in venture capital funds often gives foundation and endowment managers heartburn. The first venture portfolio fund of Kleiner Perkins Caufield \& Byers held 17 companies, and over an 11-year horizon produced a $31 x$ return and an IRR of $51 \%$. However, $91 \%$ of the fund's return came from two investments in Tandem Computers (105x) and Genentech (236x). ${ }^{[3]}$ A prominent critic of the venture capital model -- its marketing, fees and performance -says that venture capitalists are "paid to lose money." [4]

As much as venture capital is a means to finance innovation, its pricing model has not innovated or changed much since its inception. Nothing changes in financial markets unless buyers rebel. To simply rail against the status quo is to tilt at windmills.

The Kauffman Foundation's report, along with other academic and industry studies, show that superior performance in venture capital and private equity investing comes from investing with a relatively small set of the longer-lived, more successful fund sponsors. Generally, these sponsors have a larger base of assets under management.

In 2014 the largest venture funds raised were generally by sponsors with a track record of demonstrated success. ${ }^{[5]}$

|
\begin{tabular}{|l|l|l|l|l|}
\hline Firm & Early Stage Inv. & Deal Count & Avg. Investment & Assets Managed \\
\hline Andreesen Horowitz & $\$ 1.0$ billion & 50 & $\$ 20$ million & $\$ 4.4$ billion \\
\hline Khosla Ventures & $\$ 809$ million & 45 & $\$ 18$ million & $\$ 3.1$ billion \\
\hline SV Angel & $\$ 736$ million & 47 & $\$ 16$ million & $\$ 104$ million \\
\hline Accel Partners & $\$ 721$ million & 29 & $\$ 25$ million & $\$ 9.6$ billion \\
\hline NEA & $\$ 690$ million & 44 & $\$ 16$ million & $\$ 13$ billion \\
\hline Xeareck & $\$ 660$ million & 15 & $\$ 44$ million & $\$ 2.6$ billion \\
\hline Sequoia Capital & $\$ 650$ million & 30 & $\$ 22$ million & $\$ 10$ billion \\
\hline
\end{tabular}

Investors flock like lemmings to success. Investors in an existing fund with an elite venture capital sponsor will feel lots of pressure to invest in the sponsor's next fund; venture investors are fearful of being shut out of the next fund that might contain within it the next Apple or Facebook. If an institutional investor objects to the 2/20 model, another investor is ready and willing to take its place in investment queue.

\section{Not a Lot of Differentiation among Industry Targets of Venture Funds}

Data from Dow Jones VentureSource indicates that California ranks \#1 among states with the total amount of venture investment with $\$ 29.8$ billion, or $57 \%$ of the total invested. More than forty years after the golden age of venture capital, Silicon Valley is still the Hollywood of finance. 
Out of $\$ 49$ billion invested in all venture deals in 2014 , the largest industry share went to software investments, amounting to $\$ 20.5$ billion, according to PwC/Money Tree. Life sciences (biotech and medical devices) took the number share with $\$ 8.5$ billion, while media and entertainment took third place with $\$ 5.9$ billion.

Software-driven investments are very attractive for several economic reasons. Software companies can generate saleable product relatively quickly, compared to say biotechnology companies, and the cost of renting computing power, using options like Amazon Web Services, has dropped what were once significant fixed investments into variable costs. West Coast schools, and global graduates, are producing talented architects, programmer/analysts, and coders. I serve on the advisory board of a private equity software company, located in New England, which had to relocate in order to get a better supply of programmers and developers for their next generation of products.

\section{Should Your Startup Look for Venture Capital?}

Out of the $500,000-600,000$ new businesses incorporated each year, a reader can infer from the numbers in this commentary that very few companies actually receive venture funding, perhaps less than 1 percent of the startup universe. So, entrepreneurs must keep in mind that the marquee success stories like Apple, Google or Facebook are culled from an already tiny universe of companies receiving venture funding. Your odds are long from the get-go. What are some of the things venture capital firms need to see before your company can make the cut for a seed round or a Series A round?

\section{Large Addressable Market}

A critical number that all investors look for, whether public or private, is the company's total addressable market ("TAM"). As a public company CFO, I had to quickly revise our company's TAM, generated before my time and wildly optimistic. After recasting it, qualifying it and supplying assumptions, it was reviewed by the SEC as part of our disclosure review, and it passed. Private companies have very little restraint on their TAM estimates, but suffice it to say that if your TAM is less than $\$ 1$ billion for your initial product and near-term enhancements, don't waste time thinking about VC funding.
Software companies, such as Tableau and Box, have large addressable markets, the former in business intelligence systems and data analytics, and the latter in cloud storage for individuals and companies. In some cases, the market has already been defined by earlier products or systems and in others, like cloud storage, hundreds of companies are flooding into a new medium. Either way, you have to make a convincingly numerate case why you can enter this market quickly with a saleable product, gain share with an efficient distribution model, and perhaps have the market itself expand as a result of your product introduction.

Uber is the example of a disruptive service that turns a large, existing market of cars-for-hire upside down. Professor Aswath Damodoran of the Stern School of Business has estimated Uber's global TAM for taxi and car service at $\$ 100$ billion. Venture capitalist Bill Gurley of Benchmark Capital, an A Round investor in Uber, argues that over time network effects will expand the TAM to some 25 times Damodaran's estimate. I inject this real-life example because it is the one I always have in mind when analysts talk about a "disruptive" service or product. Because Uber had rapid uptake in the San Francisco market -- measured by drivers, utilization and revenue -- it was able to grow its valuation at unprecedented rates. If your startup company has this kind of disruptive model, which needs very little capital investment, then you will have a lot of venture capital firms looking at it.

\section{Rapid Introduction and Uptake of Saleable Product or Service}

Investors don't like investments with non-controllable risks, e.g. regulatory risks. Medical devices, once the cornerstone of venture capital investment and rapid exits, have fallen out of favor. For example, a company with a novel drug-eluting stent with a bioabsorbable coating will need extensive pre-clinical feasibility and safety data, and then a randomized, double-blind clinical study to prove patient effectiveness. This takes years and millions of dollars, and is a zero-one wager.

Software, by contrast, is a desirable investment sector because the market is large and expanding, there are very few IP barriers to entry, computing costs are dropping, developers are available worldwide, and it's relatively easy to get some traction in a corner of a market to demonstrate a saleable product. Revenue is always a good thing for software companies. 
Healthcare investments once meant medical devices and biotechnology companies. Today it means healthcare informatics companies, patient diagnostic and monitoring technology companies, and still biotech companies in novel areas like immunology. Healthcare informatics and patient monitoring companies are like software companies in that the guts of the products are likely software driven, and they are not regulated like medical devices; they can also be privately funded or reimbursed by insurance companies. Coming to market quickly and driving revenue is what investors want to see.

Long development cycles and product introduction delays are anathema to venture capital investors.

\section{Strong and Credible Management Teams}

Investors are really investing in the startup's management team. At Twitter, co-founders Evan Williams, Jack Dorsey, Biz Stone and Noah Glass were a diverse team, some of whom were already known to the venture community through other ventures or through their corporate employers. A good division of labor; teamwork; a shared, passionate commitment and an ability to communicate and engage with your user community and investors are essential to make your company stand out from a crowd.

\section{A Plausible Exit Plan}

As we've pointed out at some length, venture firms looking at the progress of their portfolio of companies in a fund will have an idea which ones can accrete value relatively quickly, without substantial injections of funding rounds, and which ones are strong candidates for a sale to a strategic buyer or an IPO. Three to five years will be an important decision period for the fund managers. If your company's path to an exit is not clear and you haven't hit your marks, your company will be capital starved.

The institutional investors discussed here, like the Kauffman Fund, find it difficult to stomach annual volatility of returns from venture capital/private equity, and won't hang onto an investment for seven to 10 years without significant exits and return of capital. Don't miss your revenue ramp early or often because (1) you'll probably be replaced as CEO, and (2) your company may be starved of additional funding rounds and be stuck in a long-lived, zombie fund, earning the wrath of investors and the disdain of your peers.
Your venture capital firm needs to focus on the exit plan with the given time horizon. As a CEO/Founder, you and your team have to deliver the product or service to the market on time, distributed efficiently, with a tight grip on product development and corporate expenses in order to help the venture firm and its investors to get what they want out the venture capital market. If you do your jobs, the value accretion and buzz will be your rewards.

\section{What Else?}

Have your own advisory team in place early. Look for experience, competence, trust and an enthusiasm for helping you succeed. Make sure that you don't abuse friendships, and let the advisors know how they will be compensated.

\section{What Can You Expect If You Are Funded?}

Your company will be assigned a Managing Partner who will become a board member, and your board will take shape driven by the lead investor. Some other partner(s) will interact very often with your financial/accounting function to monitor budgets and cash management. Get used to micro-control: it's a cost of business, and it's their investors' money. A good firm with good Managing Partners, depending on the venture firm's culture and style, will be a good sounding board for you, but they are not there to be your friends. Those have to exist outside of your funding relationship with the venture capital firm.

\section{What's Next for Venture Capital? Near-Term Cycle Looks Positive}

We spent a lot of time at the beginning of this commentary talking about venture capital/private equity returns and about the growth in public company capitalizations. It's important because, given the healthy returns from publicly traded bonds and stocks, expected future returns are generally lower given concerns about $\mathrm{P} / \mathrm{E}$ multiple valuations in a low-growth global economy. Potential higher returns from alternative assets, especially venture capital, look more mouthwatering than ever, relative to returns from public, liquid markets.

Perhaps the exemplary data point for investor appetite is the size and composition of the latest venture funds raised by New Enterprise Associates ("NEA"), www.nea.com(http://www.nea.com) . On April 15, 2015, NEA announced the closing of its 15th flagship fund, the biggest in the industry's history, at approximately $\$ 2.8$ 
billion. Some of the committed capital has already been called down for investment. According to Forbes, 70\% of the fund's capital will be committed to technology, and $30 \%$ to healthcare. NEA raised an additional $\$ 350$ million for a fund focused on later-stage investments in emerging companies. This fund seems targeted at a new group of venture capital investors, namely the public mutual fund companies, like T. Rowe Price, which are looking to make late-stage investments in private companies ahead of planned IPOs.

The demand for funds from top-tier sponsors continues unabated.

\section{Emerging Markets}

Many of the top-tier firms have established satellite offices in markets like India and China. Companies like Flipkart, India's Amazon-like online retailer, has rapidly grown revenues and raised somewhere around $\$ 1$ billion from a variety of investors, many of them not traditional venture capital investors.

\section{Lower Fees and Profit Participation?}

Especially since research has shown the investor's best chance of success in venture capital investing is with the top-tier firms, and since these firms are raising larger funds with higher minimums, they have no incentive to change the $2 / 20$ model, except perhaps at the margins. If, after fees, investors feel that their internal rates of return are satisfactory, as has been the case recently, then why should things change? On Wall Street, things change only if the buyers rebel.

\section{New Sectors}

The growth in older populations and the increase in traditional cardiovascular diseases among the growing middle class in emerging markets means that we need real innovation in diagnosing and treating diseases. However, I've been involved with a number of companies with these kind of potential innovations in early stages. Unfortunately they often require basic research funded by non-profit or government sources, and then they must make a transition from a university research environment to a corporate entity focused on commercialization. The time horizons, research and development expenses, and potential clinical studies are not typically what venture capital firms and investors like to see.

Juno Therapeutics provides an example of the market taking a different tack to this new sector. Juno
Therapeutics began its corporate existence in 2013 with IP and research capability coming out of a cancer research environment. Initial funding, from traditional venture capital firms and some non-traditional partners, raised a $\$ 145$ million Series A round, which is eyepopping for a preclinical company with no revenue. The company became public as a preclinical company, which is again not the traditional model. Certain types of public market institutional investors may have the patience to let this company hit its clinical targets and do follow-on equity offerings. Juno bears watching as a model for some other biotechnology companies.

\section{Conclusion}

Entrepreneurship is certainly broader than the set of companies funded by venture capital. Venture capital firms are intermediaries between the providers of capital and the companies needing funding. Investors don't have the staff and experience to find suitable venture targets, and they don't want to manage or oversee companies. Venture capital companies offer the investors "deal flow," a stream of investable properties gathered into portfolios that should enhance the possibility of achieving the required excess returns. They offer a track record and experience in finding and supervising the portfolio companies.

Venture capital returns are cyclical, just like returns from other asset classes. Right now, returns are rebounding and investor appetite for funds is robust. Entrepreneurs with the right model in the favored sectors should fire up their PowerPoint presentations.

\section{References}

[1] Chris Elvin, Prequin, "Private Equity and Venture Capital in 2015."

[2] www.sequoiacap.com

[3] Wilson, John G. (1985), "Inside the High Stakes World of Venture Capital." Boston: Addison-Wesley.

[4] For a fuller critique and an examination of a real portfolio's performance, see Mulcahy, D. et al, 2012. "We Have Met the Enemy and $\mathrm{He}$ is Us: Lessons from Twenty Years of the Kauffman Foundation's Investments in Venture Capital and the Triumph of Hope Over Experience." (www.kauffman.org)

[5] Data from www.pitchbook.com, reported in Entrepreneur magazine. 